\title{
Efficacy of Solution Focused Brief Therapy, Systematic Desensitization and Rational Emotive Behavioural Therapy in Reducing the Test Anxiety Status of Undergraduates in a Nigerian University
}

\author{
Osenweugwor Ngozi Aihie, Ph. D \\ Department of Educational Evaluation and Counselling Psychology, \\ Faculty of Education, University of Benin, \\ Benin City, Nigeria \\ Martins Noyosase Igbineweka, PhD \\ Department of Educational Evaluation and Counselling Psychology, \\ Faculty of Education, University of Benin, \\ Benin City, Nigeria
}

Doi: 10.2478/jesr-2018-0002

\begin{abstract}
This study investigated the differential efficacy of Solution Focused Brief Therapy (SFBT), Systematic Desensitization (SD) and Rational Emotive Behavioural Therapy (REBT) in reducing the test anxiety status of undergraduates in a Nigerian University. To guide the study two research questions were raised and two corresponding hypotheses formulated. The study, a pre-test, post-test non-equivalent control group quasi experiment adopted a 3x2x2 factorial design. A sample of one hundred and twentythree undergraduate students in a Nigerian University participated in the study. A twenty-item Test Anxiety Inventory adapted from Spielberger (1980) was revalidated and administered to the sample to collect data for the study. The internal consistency of the instrument had a Crombach's alpha value of 0.82. Data collected were analysed using Analysis of Variance statistics and the hypotheses were tested at .05level of significance. The results revealed statistically significant decreases in test anxiety of participants in two of the treatment groups - Systematic Desensitization and Solution Focused Brief Therapy. The effectiveness of the two treatments on test anxiety was found to be independent of gender of the participants. Rational Emotive Behaviour Therapy had no statistically significant effect on the test anxiety of the participants. It was concluded that Systematic Desensitization and Solution Focused Brief Therapy are effective methods of reducing test anxiety in learners. Based on the results, recommendations were made.
\end{abstract}

Keywords: Efficacy, Therapy, Test Anxiety, Undergraduates.

\section{Introduction}

Counselling psychologists have over time; asserted that anxiety plays a major role in the lives of individuals. Anxiety is a common reaction to stress and often results in frustration and this is capable of affecting the totality of the individual as well as his/her personality (Omoluabi, 2003). Striving for academic excellence in the school can be stressful such that students become apprehensive over evaluation as it relates to academic performance. Tests are normal components of school life and have great impacts on students' grades and future academic success. Test anxiety or apprehension over academic evaluation as it relates to academic performance is characterised by cognitive, behavioural and physiological reactions which result from academic 
testing. Researchers have reiterated that to some extent, academic success depends upon students' ability to adapt to academic situations. People of all ages are evaluated with respect to their achievement, skills and abilities and tests and examinations at all levels of education have been considered important and powerful tools for measuring academic excellence and attainment which are regarded as parameters for recruitment, placement and advancement in both public and private organisations. They are also parameters adopted in the selection of candidates for admission into tertiary institutions (Iroegbu, 2013). Test anxiety is characterised by cognitive, behavioural and physiological reactions which result from academic testing. Egbochuku, Obodo and Obadan (2008), observed that many secondary school students in Nigeria feel uneasy, fearful and anxious as tests approach while some even go to the extent of feigning sickness. In the same vein, Nwankwo, Obi and Obi (2014) also asserted that many students, at the verge of sitting for school tests exhibit some restlessness, trembling, fidgeting and panic. Test anxiety can have negative effects on students' emotional development and behaviour and also affect their feelings about self and school (Salend, 2012). Anxiety has been found to be a major predictor of academic performance (McCraty, 2007; McCraty, Dana, Mike, Pam and Stephen, 2000). Research reveals that highly test anxious students score about ten percentile below their low anxiety peers (Mc Donald, 2001, Cassidy \& Johnson, 2001). While some amount of anxiety is normal and often helpful and indeed required in keeping the individual mentally and physically alert (Ghani and Spielbeger, 2012), people who experience test anxiety report a lot of stress and anxiety before, during and after the test as they often ruminate about how poorly they performed. This can result in school avoidance and increase in dropout rate. As rightly asserted by Adeola and Adedipe (2003), anxiety over test situations is an emotional problem for many students, which if not attended to could result in neurotic difficulties.

In a bid to find solution to the problem of test anxiety, psychotherapeutic approaches have been employed by counselling psychologists and school counsellors. Among these are Systematic Desensitisation (SD), Rational Emotive Behaviour Therapy (REBT) and Solution Focused Brief Therapy (SFBT). Systematic Desensitisation (SD) is a behavioural technique in which a person is gradually exposed to an anxiety -producing object, event or place while in some form of relaxation at the same time in order to reduce the symptoms of anxiety. It is based on the principle of classical conditioning by Wolpe in the 1960s. SD as a method has consistently proven to be effective in the treatment of anxiety and phobias (Richmond, 2017). Systematic Desensitisation (SD) has been found to be effective in reducing test anxiety among Nigerian Secondary School students (Anyamene, Nwokolo and Azuji, 2015; Askhia, 2014; Otta and Ogazie, 2014; Egbochuku and Obodo 2005 and Egbochuku, 1998). Similar results were obtained in Jordan by Abood and Abumelhim (2015). Rational Emotive Behaviour Therapy (REBT) introduced by Albert Ellis is an approach to counselling and psychotherapy that focuses on uncovering irrational beliefs which lead to negative and unhealthy feelings and replacing them with more productive rational alternatives (Egbochuku, 1997, Igbineweka, 2015). REBT's basic hypothesis is that emotions stem from beliefs which in turn influence evaluations and interpretations of life's situations (Corey, 2013). In the therapeutic process, clients learn skills that enable them identify and dispute irrational beliefs and replace them with effective and rational cognitions. REBT approach has been found to be effective in the reduction of test anxiety among learners (Obodo, 2006; Oliha, 2010). Solution Focused Brief Therapy (SFBT) also called Solution-Focused Therapy was developed by de Shazer and Berg in the 1980s (Bannink, 2007). Solution Focused Brief Therapy as the name suggests, is a competency-based model which minimizes emphasis on past failings and problems but instead focuses on clients' strengths and previous successes. SFBT proposes: the development of a solution is not necessarily related to the problem; the client is the expert; if it is not broken, do not fix it; if something works, continue with it; if something does not work, do something else (de Shazer,1985 cited in Bannink, 2007 and Egbochuku,2012). It is conducted through direct observation of clients' responses to a series of precisely constructed questions. Positive results have been obtained in the use of SFBT in the treatment of social anxiety (Baijesh, 2015; Igbineweka, 2015). 


\subsection{Rationale for the Study}

Test anxiety has been found to be prevalent on University campuses and to negatively impact academic progress as well as mental and physical health (Darner \& Melendes, 2011). The nature of test anxiety is heterogeneous and in opposition to the desired outcomes of Education. Test anxious individuals not only perform poorly academically but are also less motivated when exposed to evaluative situations (Hancock, 2010)

The debilitating effects of test anxiety are not easily overcome without professional help (Gerwing, Rash, Gerwing, Bramble \& Landine, 2015). One therefore needs skills training and psychological treatment to improve performance and decrease test anxiety. Three therapeutic approaches to the reduction of test anxiety have been identified in this study. There is however a dearth in Literature relating to the use and effects of these therapies in reducing test anxiety among undergraduates in Nigerian Universities. The Counselling psychologists in these institutions will therefore find the results of this study a useful guide to choosing therapeutic interventions for reducing test anxiety in their clients.

\subsection{Purpose of Study}

The purpose of the study was to determine the differential efficacies of Rational Emotive Behavioural Therapy, Systematic Desensitization and Solution Focused Brief Therapy in reducing test anxiety status of undergraduates in a University in Nigeria. The study also assessed the influence of gender on the efficacy of treatments.

\subsection{Research Questions}

1. Is there a difference in the efficacies of Rational Emotive Behavioural Therapy, Systematic Desensitization and Solution Focused Brief Therapy on test anxiety status of undergraduates?

2. Is there an interaction effect in the treatment by gender on test anxiety status of undergraduates?

\subsection{Hypotheses}

1. There is no significant difference in the efficacies of Rational Emotive Behavioural Therapy, Systematic Desensitization and Solution Focused Brief Therapy on test anxiety status of undergraduates.

2. There is no significant gender by treatment interaction effect on test anxiety status of undergraduates.

\section{Methodology}

\subsection{Design of the Study}

The study adopted the pre-test, post-test non-equivalent control group quasi experimental design. The study consisted of three independent variables which are Solution Focused Brief Therapy, Systematic Desensitization and Rational Emotive Behavioural Therapy and a dependent variable, test anxiety with the intervening variable of gender having two levels (male and female).

\subsection{Participants}

The sample of the study comprised one hundred and twenty three first year undergraduate students in the Faculty of Education in a Nigerian University. Multistage random sampling procedure was used to select the sample. First, four departments were randomly selected from the five departments that make up the Faculty. Stratified random sampling was thereafter used to select a course area from 
each of the four departments selected. Adult Education Professional, Business Education, English and Literature Education and Human Kinetics were the courses selected. Intact classes of students in these course areas were then randomly assigned to the four treatment groups.

\subsection{The Instrument}

Spielberger's (1980) Test Anxiety Inventory (TAI) was revalidated and used to collect data for the study. The instrument consists of twenty items in three subscales: Test- Anxiety- Total (TAI-T), Test- Anxiety- Worry (TAI-W) and Test- Anxiety- Emotional (TAI-E). The instrument was revalidated in Nigeria by Paraform Psychometric Centre (PPC, 1997) and a Crombach's alpha value of 0.80 was obtained. Obodo (2006) obtained Crombach's alpha value of 0.90 for the same instrument. For the present study, an alpha value of 0.82 was obtained, confirming the reliability of the instrument. Responses to the instrument were on a 4-point scale of Almost Never -4 , Sometimes -3 , Often -2 and Almost Always -1.Reverse scoring was done for only item 1. The total scores were interpreted based on the Nigerian norm of 34.37 for females and 34.77 for males. Scores higher than 34.37 for females and 34.77 for males indicated typical manifestation of worrying, emotionality or general test anxiety while scores lower than the norms indicate absence of test anxiety.

\subsection{Procedure}

The participants were pre tested with the instrument to collect baseline scores. Thereafter, intact classes of students in the four course areas were assigned to the four treatment groups Systematic Desensitisation, Rational Emotive Behaviour Therapy and the control. The groups met once a week for a period of eight weeks, during which participants in group counselling sessions learnt coping skills and were encouraged to practice in everyday situations what they learnt in the group therapies. Each session lasted forty-five minutes. A convenient time and venue was chosen by each of the groups. Confidentiality among members regarding group procedures was emphasised and members encouraged not to be absent from sessions. At the end of the treatment period, the Test Anxiety Inventory was re administered on the participants. Data collected were collated and analysed using mean scores and ANOVA statistics. Post Hoc analysis was carried out where necessary.

\section{Results}

Table 1: Descriptive of Effects of Therapies on Test Anxiety Reduction at Post-test

\begin{tabular}{cccc}
\hline Post-test & $\mathrm{N}$ & Mean & Std. Deviation \\
CONTROL & 40 & 35.7000 & 9.02191 \\
SFBT & 31 & 30.5161 & 7.52273 \\
REBT & 22 & 39.0909 & 9.01274 \\
SD & 30 & 29.4667 & 3.82130 \\
\hline Total & 123 & 33.4797 & 8.41870 \\
\hline
\end{tabular}

Table 1 shows the mean and standard deviation for the groups at post-test. The table reveals that the participants in the SD treatment had the lowest mean score (29.47), followed by the SFBT group (30.52), followed by the control group (35.70) and the REBT group (39.09). The mean scores for SD and SFBT which were 29.47 and 30.52 respectively were lower than the Nigerian norm of 34.37 for females and 34.77 for males, thus indicating absence of test anxiety in participants in the two groups at post-test. This showed that there are differences in the test anxiety levels of the participants in the four treatment groups.

To determine if the differences are significant, Hypothesis 1 was tested at .05 level of significance using ANOVA statistics.

Hypothesis 1: There is no significant difference in the efficacies of Rational Emotive Behavioural Therapy, Systematic Desensitization and Solution Focused Brief Therapy on the test anxiety status of undergraduates. 
Table 2: Summary of one-way ANOVA of the effects of the therapies on test-anxiety status of the participants

\begin{tabular}{lccccc}
\hline Source of variation & Sum of Squares & d.f & Mean Square & F & Sig \\
\hline Between Groups & 1645.27 & 3 & 548.424 & 9.32 & .00 \\
Within Groups & 7001.43 & 119 & 58.836 & & \\
Total & 8646.71 & 122 & & & \\
\hline \multicolumn{7}{c}{$\mathbf{0 . 0 5}$}
\end{tabular}

Table 2 shows the $F$ value $=9.32$, d. $f=3$ and $p$ value $=.00$. The $p$ value is less than the alpha level of .05. The null Hypothesis that states that there is no significant difference in the efficacies of the treatments on test anxiety is thus rejected. Consequently, it is concluded that there is significant difference in the efficacies of the therapies in the reduction of test anxiety of the participants. To ascertain the direction, a post Hoc analysis was carried out.

Table 3: Post-Hoc Multiple comparisons of the efficacies of the Therapies on Test Anxiety Reduction

\begin{tabular}{lllll}
\hline (I) GROUPS & (J) GROUPS & Mean Difference (I-J) & Std. Error & Sig. \\
\hline \multirow{2}{*}{ CONTROL } & SFBT & $5.18387^{*}$ & 1.83543 & .02 \\
& REBT & -3.39091 & 2.03598 & .35 \\
\multirow{2}{*}{ SFBT } & SD & $6.23333^{*}$ & 1.85259 & .00 \\
& CONTROL & $-5.18387^{*}$ & 1.83543 & .03 \\
& REBT & $-8.57478^{*}$ & 2.13828 & .00 \\
REBT & SD & 1.04946 & 1.96446 & .95 \\
& CONTROL & 3.39091 & 2.03598 & .35 \\
& SFBT & $8.57478^{*}$ & 2.13828 & .00 \\
SD & SD & $9.62424^{*}$ & 2.15303 & .00 \\
& CONTROL & $-6.23333^{*}$ & 1.85259 & .35 \\
& SFBT & -1.04946 & 1.96446 & .95 \\
& REBT & $-9.62424^{*}$ & 2.15303 & .00 \\
\hline
\end{tabular}

Table 3, shows that the mean difference between SFBT and the control group (5.18387) and the mean difference between SD and the control group (6.23333) are significant in favour of SFBT and SD which had test- anxiety mean scores below the Nigerian norm for test- anxiety, indicating the absence of test- anxiety at post-test. (Table 1). The mean test-anxiety score for the participants in the control group was higher than the norm. The table also reveals a significant difference in the mean scores between SFBT and REBT (8.57478) and between SD and REBT (9.62424) in favour of SFBT and REBT. There was no significant difference between the mean scores of REBT and the Control group, both of which were higher than the test anxiety norm for Nigerian participants.

Hypothesis 2: There is no significant interaction effect of the treatment by Gender on the test anxiety status of undergraduates.

Table 4: Descriptive Statistics of Treatment by gender of participants on Test Anxiety Reduction

\begin{tabular}{lllccc}
\hline Test & GROUPS & GENDER & $\mathrm{N}$ & Mean & Std. Deviation \\
\hline \multirow{6}{*}{ CONTROL } & MALE & 16 & 36.0000 & 10.70825 \\
& & FEMALE & 24 & 35.5000 & 7.94547 \\
& & Total & 40 & 35.7000 & 9.02191 \\
& & MALE & 8 & 33.3750 & 11.03161 \\
& SFBT & FEMALE & 23 & 29.5217 & 5.86879 \\
& & Total & 31 & 30.5161 & 7.52273 \\
& & MALE & 8 & 38.0000 & 11.92836 \\
& REBT & FEMALE & 14 & 39.7143 & 7.31099 \\
& & Total & 22 & 39.0909 & 9.01274 \\
& SD & MALE & 14 & 28.9286 & 3.31580 \\
& & FEMALE & 16 & 29.9375 & 4.26566 \\
& & Total & 30 & 29.4667 & 3.82130 \\
\hline
\end{tabular}


On Table 4 is displayed the number and mean scores of participants by gender and treatment groups. The Control group had 16 males and 24 females with mean scores 36.00 and 35,50 respectively. The SFBT group had 8 males and 23 females with mean scores 33, 38 and 29.52 respectively. The REBT treatment group had 8 males and 14 females with mean scores 38.00 and 39.71 respectively. The SD treatment group had 14 males and 16 females with mean scores 28.93 and 29.94 respectively. The corresponding standard deviations are also displayed. To determine if there is any interactive effect of treatment by gender, the null hypothesis was tested at .05 level of significance. The results are displayed in table 5 below.

Table 5: Two way ANOVA of Gender by Treatment interaction effect on Test Anxiety Reduction

\begin{tabular}{lccccc}
\hline Source & Type III Sum of Squares & df & Mean Square & $\mathrm{F}$ & Sig. \\
\hline Corrected Model & $1758.362^{\mathrm{a}}$ & 7 & 251.195 & 4.194 & .000 \\
Intercept & 121771.699 & 1 & 121771.699 & 2032.965 & .000 \\
GROUPS & 1367.048 & 3 & 455.683 & 7.608 & .000 \\
GENDER & 4.406 & 1 & 4.406 & .074 & .787 \\
GROUPS * GENDER & 108.455 & 3 & 36.152 & .604 & .614 \\
Error & 6888.337 & 115 & 59.899 & & \\
Total & 146516.000 & 123 & & & \\
Corrected Total & 8646.699 & 122 & & & \\
\hline
\end{tabular}

a. R Squared $=.203$ (Adjusted R Squared $=.155$ )

The results in table 5 indicate that the interaction effect of treatment by gender has a mean square of 36.152, $\mathrm{F}$ value of .604 and a p-value of .614. The p-value is greater than the alpha level of .05. The null hypothesis is thus accepted. Therefore there is no significant interaction effect of treatment by gender on the test anxiety status of the participants.

\section{Discussion of Findings}

The results of the study reveal that Systematic Desensitisation (SD) was effective in the reduction of test anxiety of the participants in the study.

The finding lends credence to the assertion made by Head and Gross (2008) that SD is one of the most empirically supported therapy methods available, especially for treating anxiety. The result corroborates Egbochuku (1998), Egbochuku and Obodo (2005), Otta and Ogazie (2014), Azuji, Nwokolo and Anyamene (2015) who found SD effective in reducing test anxiety and test phobia among secondary school adolescents in Nigeria. It is also in consonance with Abood and Abumelhim (2015) who found SD effective in reducing anxiety among learners in Jordan.SD is a method that has been consistently proven to be effective in the treatment of anxiety and phobias. In this study, participants in the SD treatment group had the lowest mean score for test anxiety (30.52)

SFBT was also found to be significantly effective in the reduction of test anxiety of the participants. This finding for SFBT is in consonance with the findings of Taylor (2013), Javanmiri, Kimiaee and Hashem (2012), Egbochuku and Igbineweka (2013), Igbineweka (2015) and Baijesh (2015) who made similar findings. While Taylor (2013) found SFBT group counselling effective in reducing symptoms of generalized anxiety, Javanmiri,Kimiaee and Hashem(2012) found SFBT group counselling effective in reducing depression among teenage girls. Egbochuku and Igbineweka (2013), Igbineweka (2015) and Baijesh (2015) also made findings indicating the effectiveness of SFBT in reducing test anxiety and social anxiety respectively.

In the present study, REBT was found to be ineffective in reducing the test anxiety of the participants. This may not be unconnected with the low number of participants at post-test. The finding is however in contrast with Egbochuku (1998, 2002, 2008), Obodo (2006) and Oliha (2010) who found REBT effective in reducing test anxiety of students in Nigerian secondary school students. The results of the study also show that there was no interactive effect of treatment by gender on the test anxiety status of the participants. This is an indication that the treatments were effective irrespective of gender of the participants.

This result agrees with earlier findings by (Ifeanyi, Nwokolo and Anyamene, 2015); 
(Egbochuku and Obodo (2005), who also found no significant treatment by gender effect on the reduction of test anxiety of students. The study further agrees with the reports of other studies like Egbochuku and Igbineweka (2014) in which they found that Sex had no significant effect on the reduction of test anxiety of students using the Solution Focused Brief Therapy.

\subsection{Conclusion}

From the result of the study, it can be concluded that Systematic Desensitisation (SD) and Solution Focused Brief Therapy (SFBT) are effective methods of reducing test anxiety among learners and that this effectiveness is not gender biased.

\subsection{Recommendations}

The study has shown that test anxiety which is inimical to the achievement of the objectives of Education and found to be prevalent in schools, can be reduced using Systematic Desensitization and Solution Focused Brief Therapy. Counsellors in schools should therefore regularly employ these methods to help students who show symptoms of this maladjustment. Although REBT was not found to be effective in reducing test anxiety in the present study, previous studies revealed its effectiveness. Counsellors in training should therefore be effectively trained in the use of these therapies

It is also recommended that further studies be carried out using REBT to test its effectiveness in the reduction of test anxiety using a larger sample.

\section{References}

Anyamene, A., Nwokolo, C., \& Azuji, I., (2015). Effects of systematic desensitization technique on test anxiety among secondary school students. International Journal of Humanities Social Sciences and Education, 2(2), 167-178.

Adeola, A.O. \& Adedipe, N.O. (2003). Coping skills used in the treatment of test anxious students. Nigerian Journal of Educational Psychology, 2 (1). Retrieved from www.ajaol.info/

Asikhia, O. A., (2014). Effect of cognitive restructuring on the reduction of mathematics Anxiety among senior secondary school students in Ogun State, Nigeria. International Journal of Education and Research, 2, 2.

Bannink, F. P. (2007). Solution-focused brief therapy. Journal of Contemporary Psychotherapy, 37, 87-94. doi:10.1007/s10879-006-9140-y

Baijesh,A. R.(2015) Solution Focused Brief Therapy for social anxiety disorder: A pilot Study. International Journal of Psychology and Education,2(7), 8-12

Cassidy,J.C.\& Johnson, R. E.(2001)Cognitive test anxiety and academic performance. Contemporary educational psychology 27,270-298

Corey, G. (2013). Theory of Practice of Counseling and Psychotherapy. Canada: Brooks/Cole

Darner, D.E. \& Melendres, L.T. (2011).Tackling test anxiety. A group for college students. 38(3), 163-177.

Egbochuku, E.O.(1998). Differential effectiveness of Systematic Desensitisation and REBT in reduction of test anxiety. Nigerian Journal of Developmental issues 2 (2), 38-59.

Egbochuku, E. O., \& Obodo, B. O. (2005). Effects of systematic desensitization (SD) therapy on the reduction of test anxiety among adolescents in Nigerian schools, Journal of Instructional Psychology 32(4), 298-304.

Egbochuku, E. O., Obodo, B, \& Obadan, N. O. (2008). Efficacy of rational- emotive behaviour therapy on the reduction of test anxiety among adolescents in secondary schools. European Journal of Social Sciences. 6, (4).

Egbochuku, E.O. (2012). Solution Focused Brief Therapy : A Paradigm Shift, Benin City: Ambik Press ISB 9788430-51-3

Egbochuku, E.O. \& Igbineweka, M.N. (2014). The Effectiveness of solution focused brief therapy in the reduction of test anxiety amongst students in private tertiary Institutions: Edo Journal of Counselling Pg95110. 7 August, 2014. ISSN: 2006-759

Gerwing, T.,.Rash, J.A., Gerwing,A.A., Bramble,B.\&Landine, J. (2015). Perceptions and incidence of test anxiety. The Canadian Journal for the scholarship of tackling and learning, 6(3) http;//dr.doi.org/0.5206/cysotl-rcacea 205:303 
Hancock, D.R. (2010). Threat on students' achievement and motivation. The journal of educational research,94(5), 284-290

Head,,I.S and Gross, A.M.(2008).in W.O' Donohue \& J.E. Fisher (Eds) Cognitive Behaviour Therapy: Applying empirically supported technique in your practice, 542-549. Hoboken, NJ: Wiley

Ifeanyi, I., Nwokolo, C. \& Anyamene, A. (2015), Effects of systematic desensitisation technique on test anxiety among secondary school students, International Journal of Humanities Social Sciences and Education (IJHSSE) 2( 2),167-178 ISSN 2349-0373 (Print) \& ISSN 2349-0381 (Online). Retrieved $20^{\text {th }}$ September 2016 from www.arcjournals.org

Iroegbu, M.N. (2013).Effect of test anxiety, gender and perceived self- concept on academic performance of Nigerian students. Retrieved April $4^{\text {th }} 2015$ from International Journal of Psychology and Counselling. 5(7),143-146, September, 2013 DOI: 10.5897/IJPC2013.0218 ISSN 2141-2499 (C) 2013 Academic Journals http://www.academicjournals.org/lJEL

Javanmiri1, L., Kimiaee1, S.A \& Hashem Abadi1, A.B (2012). The study of solution focused group counseling in decreasing depression among teenage girls. International Journal of Psychological Studies; 5,( 1) 2013, ISSN 1918-7211 E ISSN 1918722X. Published by Canadian Centre of Science and Education, Retrieved on $30^{\text {th }}$ August 2013 from URL: http://dx.doi.org/10.5539/ijps.5(1),105

Mc Craty, R. (2007). When anxiety causes your brain to jam, use Your Heart. Institute of HeartMath.Availableonhttp://www.heartmath.com/company/proom/archive/encounterjournal_brain_jam http I (June 3, 2008).

Mc Craty, R., Dana, T., Mike, A., Pam, A., and Stephen, J. (2000). Improving test-taking skill and academic performance in high school students using heart Math Learning Enhancement Tools. Heart Math Research Centre, Institute of Heart Math, Publication No. 001-010, Boulder Creek, CA.

Mc Donald,A.(2011). Prevalence and effects of test anxiety in school children. Educational Psychology. 21(1), 89-101

Nwankwo C. A, Obi J. S. \& Obi, I. (2014). Effects of study skills technique in reducing test anxiety among secondary school adolescents in Anambra State. General studies on education, science and public issues in Africa, 4(1).

Oliha, J. A. (2010). Effects of counselling techniques in rehabilitating emotional maladjustment problem among adolescents. Retrieved on $25^{\text {th }}$ January 2014 From www.ajol.info/index.php/ejc/article/download/52688/41292

Omoluabi, P. F. (2003). "Validation of test anxiety inventory for Nigerian samples". Nigerian Journal of Basic and Applied Psychology. 3 (1) 37-4

Otta,F.E. \&,Ogazie,C.A. (2014). Effect of Systematic Desensitisation and Study Behaviour Techniques in the reduction of test phobia among in-school adolescents in Abia State. World Journal of Educational research, 1(3),1-7. Available on-line at www.jer.org

Paraform Psychometric Centre (PPC) (1997) "Test Anxiety Inventory" TIA Manual (7) PPC Nigerian Agency.

Richmond, R.W. (2017). A guide to psychology and its practice. Retrieved Oct. 9,2017 from www.Guide to psychology.com

Salend, S.J.(2012).Teaching students not to sweat the test. Phi Delta Kappa. 93(6). 20- 25

Spielberger, C. D. (1980). Test Anxiety Inventory. Preliminary Professional Manual. Palo Alto, CA: Consulting Psychologists Press. 